\title{
Industry Variation in Risk of Delaying Care During COVID-19
}

J Gen Intern Med 36(11):3621-4

DOI: $10.1007 / \mathrm{s} 11606-021-06694-9$

(C) Society of General Internal Medicine 2021

\section{BACKGROUND}

The COVID-19 pandemic has disrupted access to health care services. To decrease the spread of disease, many providers and patients have shifted to telehealth to provide services traditionally performed through in-person office visit consultations. $^{1}$

\section{OBJECTIVE}

The effects of COVID-19, social distancing, and health care utilization likely vary across patient populations. Due to both workforce demands and disparities in access, not all workers are able to telecommute and households with essential workers may be particularly vulnerable to the economic consequences of the COVD-19 pandemic. ${ }^{2,3}$

\section{METHODS AND FINDINGS}

We examined industry differences in changes in the use of outpatient evaluation and management office visit services among a large population of individuals with employersponsored private insurance before and after the COVID-19 national pandemic declaration. We used 2020 US medical claims data for services received between January 1, 2020, and August 2, 2020, from approximately 200 self-insured employers and health plans that purchased access to Castlight Health's transparency tools and benefits platform. The study population included 6.8 million individuals in 25 separate industries and has been used to examine care utilization during the COVID-19 pandemic. ${ }^{4}$ We measured use of outpatient evaluation and management office visit services by calculating the number of persons who received either in-person office visits or telehealth services per 10,000 eligible persons each

Received October 16, 2020

Accepted February 28, 2021

Published online March 26, 2021 week. We estimated multivariable regressions that test for the change in-office visit and telemedicine services following the national emergency declaration on March 13, 2020, controlling for patient age and patient sex, and including fixed effect controls for state and week, and applying robust standard errors. This study was approved by the RAND Institutional Review Board.

\section{RESULTS}

Figure 1 presents the share, relative to pre-COVID utilization rates, of in-person office visit services that shifted to telemedicine and the net change in primary care services. In every industry, the observed increases in telehealth utilization were not large enough to offset the decline in-office visits. Automotive workers and their dependent family members experienced the largest relative decline in in-person office visits. Inperson visits declined by $68.8 \%$ and $25.3 \%$ of clinician visits shifted to telehealth, for a net reduction of $43.0 \%$ in use of clinician visits for automotive workers. The next four industries with the largest relative decline in total healthcare utilization from baseline were medical devices $(-34.4 \%)$, chemicals $(-25.8 \%)$, oil, energy, and utilities $(-22.0 \%)$, and retail $(-17.4 \%)$. The smallest changes in total clinician visits were observed for software and technology $(0.05 \%$ net change), transportation $(-2.1 \%)$, hospitals and health care $(-5.9 \%)$, and non-profit industries $(-6.6 \%)$. Regression results showed reductions in the number of in-person office visits for every industry ( $p$-value $<0.01$ for all, Table 1 ). Separately, each of the 25 industries had an increase in telehealth utilization.

\section{DISCUSSION}

The COVID-19 pandemic and government responses to it have disrupted the employment status and healthcare utilization of individuals worldwide. Our findings suggest that these impacts have not been borne equally across employment sectors. These differences could be explained by differing impacts of the COVID-19 pandemic across industries on employment and earnings, differences in insurance benefit 


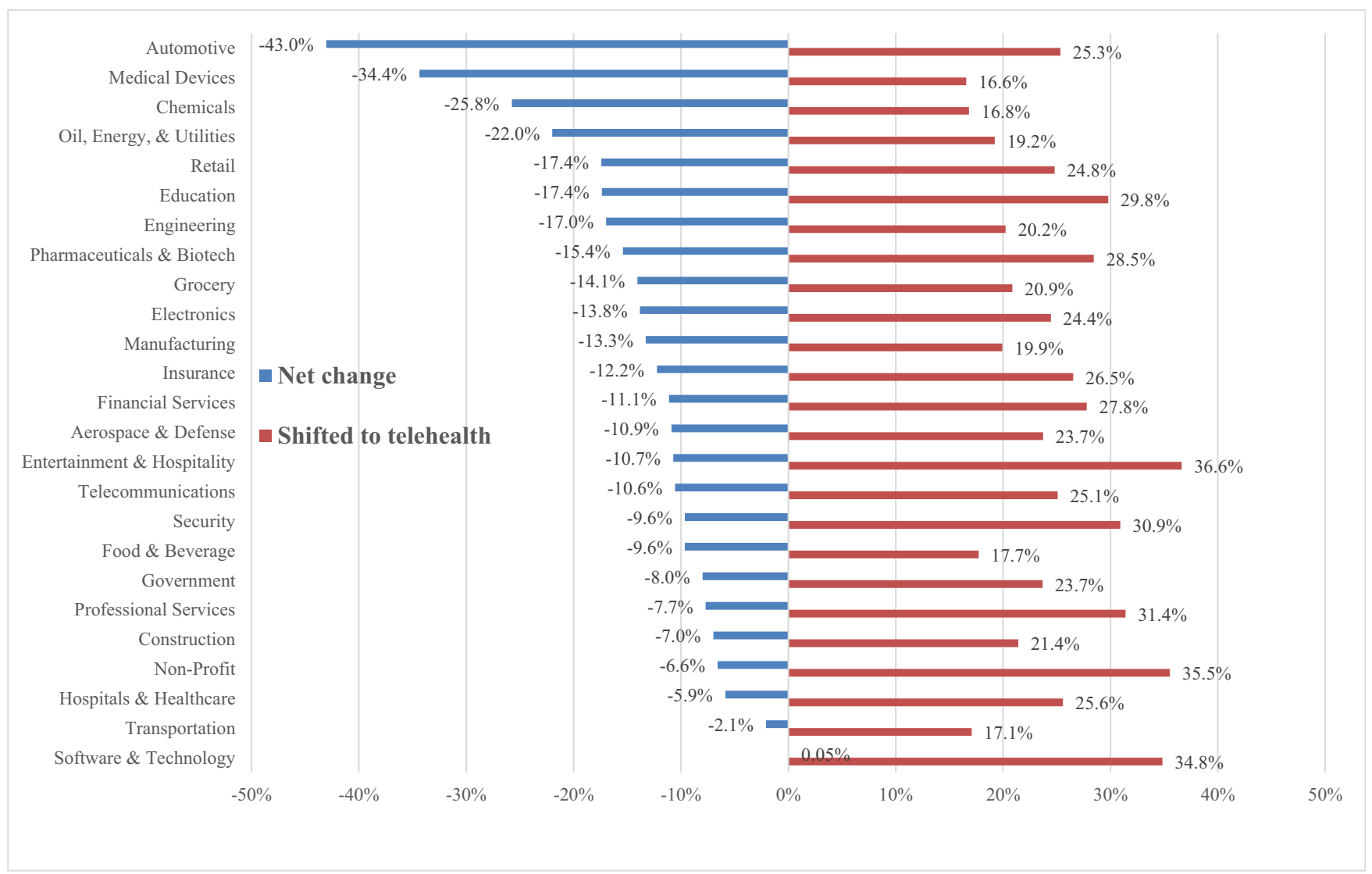

Figure 1 Changes in office-based care utilization by industry. This figure shows the regression-adjusted relative change in consultations, either in-person or telemedicine, that shifted to telemedicine and the net change.

design generosity, or ability to work from home or access to telehealth from home. ${ }^{5,6}$ Future research should examine the specific forms of care that are being disproportionately deferred across industries and ascertain whether they are elective or non-elective procedures.

This study is not without limitations, including our focus on patients with private insurance provided by an employer and thus does not include patients who lost health insurance due to job loss during the COVID-19 pandemic. However, our results provide a critical snapshot of the drastic shock to the health care delivery system created by the COVID-19 pandemic. In particular, the decline in healthcare utilization across industries suggests that policymakers and public health officials must do more to ensure that workers in these industries continue to receive needed care. Our data do not allow us to examine the health impacts of delayed care, but future work should test how delayed care due to COVID-19 and relatedpolicies have impacted the health outcomes of all patients, but industry-specific disparities exist in care reductions. 


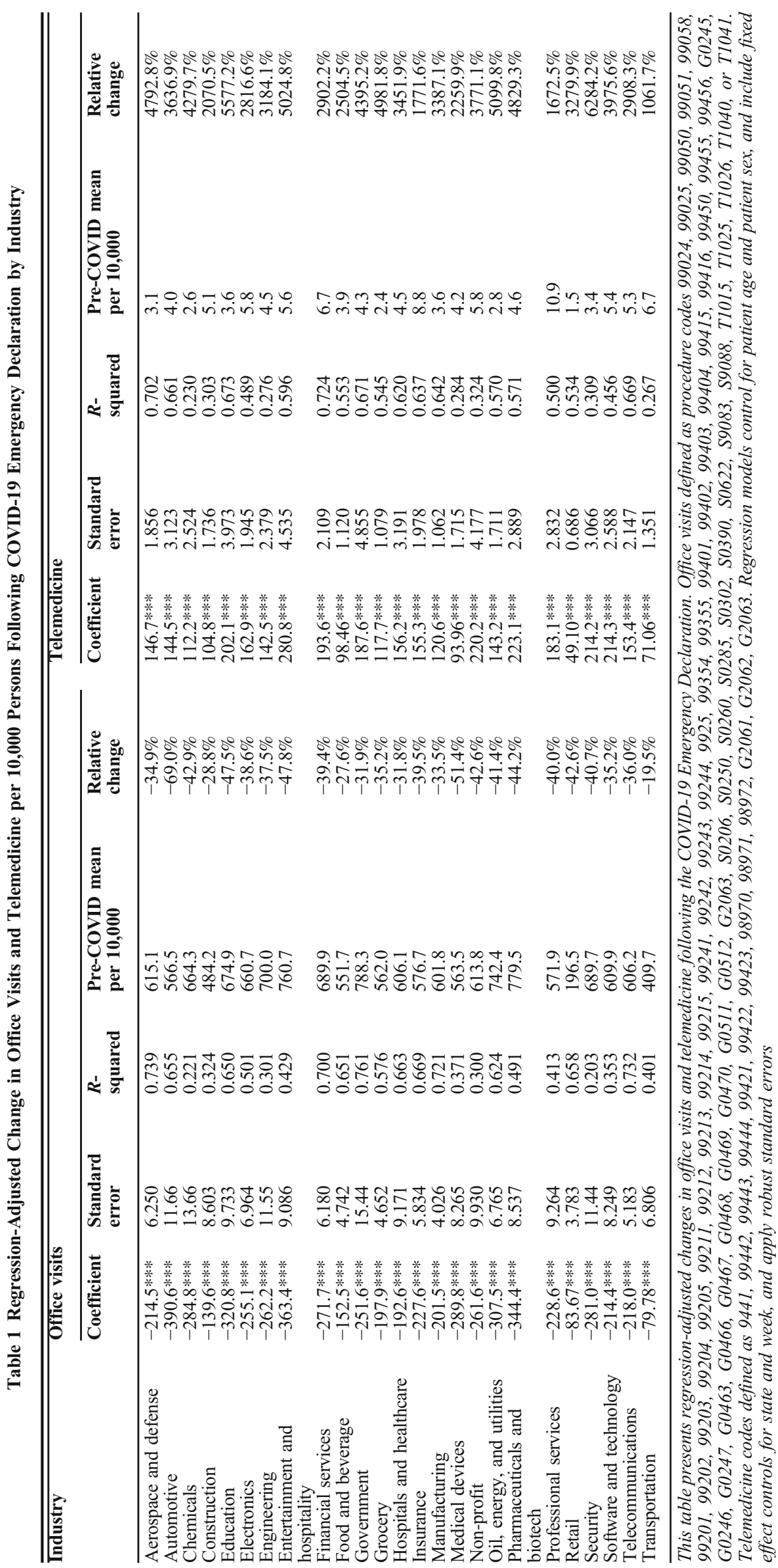


Christopher M. Whaley, Ph.D. ${ }^{1}$

Jonathan Cantor, Ph.D. ${ }^{1}$

Megan F. Pera, M.S. ${ }^{2}$

Dena M. Bravata, M.D., M.S $S^{2,3}$

${ }^{1}$ RAND Corporation,

1776 Main Street, Santa Monica, CA 90401, USA

${ }^{2}$ Castlight Health,

San Francisco, CA, USA

${ }^{3}$ Center for Primary Care and Outcomes Research,

Stanford, CA, USA

Corresponding Author: Christopher M. Whaley, Ph.D.; RAND Corporation, 1776 Main Street, Santa Monica, CA 90401, USA (e-mail: cwhaley@rand.org).

Funding Support was provided by the National Institutes on Aging (1K01AG061274, Whaley).

\section{Declarations:}

Disclaimer: The funding sources had no role in the design and conduct of the study; collection, management, analysis, and interpretation of the data; and preparation, review, or approval of the manuscript.
Conflict of Interest: The authors declare that they do not have a conflict of interest.

\section{REFERENCES}

1. Wosik J, Fudim M, Cameron B, et al. Telehealth transformation: COVID19 and the rise of virtual care. J Am Med Inform Assoc. 2020;27(6):957962. doi:https://doi.org/10.1093/jamia/ocaa067.

2. Baker MG. Nonrelocatable Occupations at Increased Risk During Pandemics: United States, 2018. Am J Public Health. Published online June 18, 2020:e1-e7. doi:https://doi.org/10.2105/AJPH.2020.305738.

3. McCormack G, Avery C, Spitzer AK-L, Chandra A. Economic Vulnerability of Households With Essential Workers. JAMA. Published online June 18, 2020. doi:https://doi.org/10.1001/jama.2020.11366.

4. Whaley C, Pera M, Cantor J, et al. Changes in Health Services Use Among Commercially Insured US Populations During the COVID-19 Pandemic. JAMA Network Open. 2020;3(11).

5. Crossley TF, Fisher $\mathbf{P}$, Low $\mathbf{H}$. The heterogeneous and regressive consequences of COVID-19: Evidence from high quality panel data. Journal of Public Economics. 2020;193:104334.

6. Brynjolfsson E, Horton JJ, Ozimek A, Rock D, Sharma G, TuYe H-Y. COVID-19 and Remote Work: An Early Look at US Data. National Bureau of Economic Research; 2020.

Publisher's Note: Springer Nature remains neutral with regard to jurisdictional claims in published maps and institutional affiliations. 